\title{
DIE GEMOLESTEERDE KIND AS GETUIE
}

\author{
E. Grey
}

Departement Strafreg

Potchefstroomse Universiteit vir $\mathrm{CHO}$

POTCHEFSTROOM

\begin{abstract}
The accusatorial principle provides the basis for the South African law of criminal procedure. In practice this results in the abused child being subjected to substantial trauma when it is called upon to give evidence in such a case.

The abused child is oflen still battling to regain its self-esteem and self-confidence at the time of the trial. By subjecting the abused child to the giving of evidence and being cross-examined in the presence of the accused, the child's chances of regaining its self-esteem are rendered very slim indeed. In the interest of the abused child, and to satisfy the requirement of justice for all, an alternative to the existing system has to be found. In order to improve on the current situation, it is the author's submission that a form of procedure should be adopted through which the appearance of the abused child in coun during such a trial will be obviated. Some specific proposals to achieve this are made by the author.
\end{abstract}

\section{INLEIDING EN PROBLEEMSTELIING}

This boy's life has already been shattered by years of unthinkable abuse. The threats on him were so great that he would never have been able to disclose the matter himself. Discovery was accidental and since then he has been gradually building himself up again with the aid of intensive therapy. And yet, here in the "cause of justice" he is being completely broken down again by die court procedure which is not only permitted, but apparently demanded by our judicial system (Key, 1988:55).

Uit bogemelde aanhaling blyk dit duidelik dat getuienislewering vir die seksueel gemolesteerde kind 'n traumatiese ervaring kan wees. Dit is die oogmerk van hierdie artikel om die probleme wat die kindergetuie in strafregtelike verrigtinge ondervind, asook die gevolge daarvan vir die regsproses, kortliks in oorweging te neem. Daarna sal gepoog word om 'n moontlike alternatiewe proses voor te stel wat sowel die belange van die kindergetuie as geregtigheid kan dien.

Gedurende Augustus 1985 het 'n strafsaak in 'n Durbanse landdroshof gedien waarin twee seuntjies, waarvan die oudste twaalf en die jongste twee jaar oud was, getuienis moes aflè. Mediese getuienis ten aansien van albei het bewys dat sodomie gepleeg was oor 'n lang tydperk. Die oudste seuntjie moes gehospitaliseer word ten einde intensie- 
we sielkundige behandeling te ondergaan. Na sy ontslag moes die terapie voortgesit word.

Ongeveer agt maande nadat die saak aanhangig gemaak is, het die hofsaak 'n aanvang geneem. Tydens die verloop van die verhoor het die oudste seuntjie ernstige tekens van angs getoon. Hy het deurgaans sy hand voor sy gesig gehou sodat hy nie sy vader in die beskuldigdebank hoef te sien nie. Onder kruisondervraging moes hy herhaaldelik al die insidente in fyn besonderhede beskryf asook hoe sy pa telkens gedreig het dat hy hom met 'n mes sou doodmaak indien hy die voorvalle sou rapporteer.

Nadat die saak verskeie kere uitgestel is, is kruisondervraging ongeveer 'n jaar later hervat. Weer moes hy, maar nou aan 'n nuwe regsverteenwoordiger, die intieme besonderhede herhaal. Hy het steeds met sy hand voor sy gesig getuig. Hy is vir ure aaneen aan felle kruisondervraging onderwerp. Hy moes vrae beantwoord oor datums, tye en volgorde van gebeure wat hy nie meer kon onthou nie. Binne die eerste tien minute is hy daarvan beskuldig dat hy die storie oor die molestering versin het. Hierna het hy ineengestort en gepleit dat die regsverteenwoordiger hom asseblief moes glo (Key, 1988:54).

In $S \vee V$ het 'n negentienjarige man in die Rondgaande Hof op Nylstroom tereg gestaan op 'n aanklag van verkragting. Die klaagster was 'n vyfjarige dogtertjie van die huiseienaar by wie hy geloseer het. Die getuienis van haar moeder en die distriksgeneesheer het bo redelike twyfel bewys dat die dogtertjie seksueel gemolesteer is. Sy het daarna die getuiebank betree, maar nadat sy 'n keer of wat na die beskuldigde gekyk het, het sy geweier om enigiets te sê. Ten spyte van die simpatieke aanmoediging deur die regter, die staatsadvokaat en haar moeder, het sy geweier om haar verhaal, wat sy enkele minute tevore in die privaatheid van die staatsadvokaat se kantoor aan hom vertel het, in die teenwoordigheid van die beskuldigde te herhaal. $\mathrm{Na}$ heelwat vertraging het sy haar aanvanklike weergawe gewysig deur bloot te getuig dat die beskuldigde haar met sy vinger beseer het. Op grond van hierdie getuienis kon die hof die beskuldigde slegs aan onsedelike aanranding skuldig bevind.

Hierdie twee voorbeelde illustreer twee wesenlike probleme wat met die aanbied van die getuienis van die kindergetuie ondervind word, naamlik:

* dat die kind verplig is om in teenwoordigheid van die molesteerder te getuig2; en

\footnotetext{
${ }^{1}$ Ongerapporteer saaknommer CC 438/85.

2 Art 158 van die Strafproseswet 51 van 1977 lui soos volg: "Bchalwe waar hicrdic Wet of 'n ander wet uitdruklik anders bepaal, vind alle strafregtelike verrigtinge in 'n hof in dic aanwesigheid van
} 
* dat die kind deur die beskuldigde of sy regsverteenwoordiger aan kruisondervraging onderwerp kan word. ${ }^{3}$

\section{GETUIENISLEWERING IN DIE TEENWOORDIGHEID VAN DIE BESKULDIGDE}

Die bepalings van artikel 158 van die Strafproseswet is gebiedend. 'n Beskuldigde is daarop geregtig om die getuie te sien en te hoor getuig. Nie-nakoming van hierdie artikel het tot gevolg dat die verrigtinge op grond van 'n onreëlmatigheid, ter syde gestel kan word 4 .

\section{KRUISONDERVRAGING VAN DIE KINDERGETUIE}

Hoewel daar in die Suid-Afrikaanse reg streng voorskrifte met betrekking tot onregverdige, onbeskofte en onbehoorlike kruisondervraging bestaan ${ }^{5}$, is daar geen beletsel teen spot, sarkasme en versoeke dat die kind sy weergawe moet herhaal nie (Hiemstra, 1987:370). Daarbenewens het kruisondervraging juis ten doel om ongeloofwaardigheid aan die kant van die getuie bloot te lê of feite aan die lig te bring wat die beskuldigde se saak kan versterk. Dit is dus nie vreemd dat die kindergetuie, soos baie ander getuies, dikwels òf uitdruklik of by wyse van suggestie moet hoor dat hulle die "storie" oor die molestering versin het nie. Vir'n baie lang tydperk na die werklike molestering beleef die gemolesteerde kind emosionele onstabiliteit en vertwyfeling. Geloofwaardigheid is vir hom van wesenlike belang. 'n Bewering van leuenagtigheid kan dus die emosionele herstelproses van so ' $n$ kind in 'n groot mate belemmer.

Die prosedure van die strafhowe is deur volwassenes vir volwassenes ontwerp. Slaag die kindergetuie nie die toets van kruisondervraging aan die hand van dieselfde reëls wat vir ' $\mathrm{n}$ volwassene geld nie, weier hy om te getuig of weerspreek hy sy aanvanklike weergawe, argumenteer regsgeleerdes gewoonlik dat die kind of

\footnotetext{
die beskuldigde plaas."

3 Art 166(1) van die Strafproseswet 51 van 1977 bepaal: "'n Beskuldigde kan 'n getuie wat ten

behoewe van die vervolging ... opgeroep word ... om tc getuig ... kruisvra ... ."

${ }^{4} S$ v Motlatla 19751 SA 814 (T), $S$ v Eyden 19824 SA 141 (T).

${ }^{5} S v$ Azov 19741 SA $808(\mathrm{~T}) ; S$ v Omar 19822 SA 357 (T); $S$ v Gidi and Another 19844 SA 537

(K); S v Tyebela 19892 SA 22 (A) en $S v$ Gwebu 19884 SA 155 (W).
} 
* 'n leuenagtige, ò

* 'n onbetroubare getuie is, en dat sy of haar getuienis gevolglik verwerplik is.

Die getuienis van 'n kind word reeds sedert die sewentiende eeu met skeptisisme bejeën. Op grond van die algemene opvatting dat kinders verbeeldingryk en vatbaar vir suggestie deur ander persone is, is die sogenaamde "versigtigheidsreëls" ontwikkel en van toepassing gemaak op sekere klasse getuienis. ${ }^{6}$ Hierdie "versigtigheidsreëls" is nie wetsvoorskrifte nie. Dit behels bloot dat die verhoorhof moet soek na "waarborge van u aarheid" (Schmidt, 1989:112) ten opsigte van die kind se getuienis. Die appèlhofuitspraak in Woji v Santam Insurance Co $\mathrm{Ltd}^{7}$ is aanduidend van dié benadering:

The danger of believing a child where his evidence stands alone must not be understated.

Waar die kind 'n klaer in 'n seksuele misdaad is, moet die howe gevolglik sy getuienis "dubbel versigtig" benader. Dit is egter ironies dat 'n ondersoek van Hammond en Hammond (1987:11 e.v.) aantoon dat hierdie wantroue in die kind as getuie misplaas is. In eksperimente met moeders en hul kinders tussen vyf- en sewe jaar oud het die kinders beter as hul moeders gevaar in toetse ten opsigte van herkenning, memorisering en herinnering.

Volgens Myers (1986: par. 4.29) is dit uiters seldsaam dat 'n kind opsetlik 'n leuen sal vertel ten opsigte van seksuele molestering. By jong voorskoolse kinders ontbreek seksuele ervaring om in besonderhede 'n storie daaroor te kan fabriseer.

Is die ongekwalifiseerde aantyging teen die kindergetuie gedurende kruisondervraging dat hy 'n storie versin en leuens aan die hof vertel dan billik? Myns insiens moet daar eerder gepoog word om te verstaan waarom die kind as getuie dikwels faal in sake rakende seksuele molestering.

${ }^{6}$ Onder andere: kindergetuies, klaagsters in seksucle misdade, lokvinke, spioene en informante.

${ }^{7} 19811$ SA 1020 (A) op 1028E. 


\subsection{Gemeenskaplike kenmerke van die seksueel gemolesteerde kind}

Hoewel die simptome van die gemolesteerde kind van geval tot geval mag verskil, word gemeenskaplike kenmerke tog gevind. In navolging van Amerikaanse kundiges, word ook reeds in Suid-Afrika erkenning verleen aan die sogenaamde sexual abuse accommodation syndrome wat as versamelnaam dien vir die gemeenskaplike kenmerke van die gemolesteerde kind.

Meyers (1986:par. 4.15) beskou die volgende kenmerke as gemeenskaplik aan feitlik alle gemolesteerde kinders:

1. Secrecy.

2. A feeling of helplessness.

3. A sense of being trapped by the situation.

4. Accommodation to the abuse.

5. Nightmares (especially nightmares with an assaultive content).

6. Sleep disturbance.

7. Loss of appetite.

8. Regressive behaviour.

9. Pseudo-mature behaviour.

10. Withdrawal.

11. Acting out.

12. Difficulty recalling details such as dates and times.

13. Fear of men.

14. Fear of further abuse.

15. Depression and anxiety.

16. Embarrassment at peer's knowledge of the abuse.

17. A negative view of sex.

18. A poor relationship between mother and daughter.

19. Running away from home.

20. Doubt that the nonabusing parent is strong enough to protect the child.

21. Conflicting versions of events.

22. Inarticulate descriptions.

23. Drawings by the child which contain enlarged sexual organs, and in the case of male genitalia, an erection and/or ejaculation.

24. Knowledge of sexual matters which would not be possessed by a child of the particular age unless the child had been exposed to information about sex or the sex acts. 
25. Use of sexual words of which a child of the particular age would have no knowledge unless the child had been exposed to the words.

26. Use of anatomically correct dolls in ways that are inexplicable for a child of the particular age unless the child has experienced sexual contact.

27. Delay in reporting abuse.

28. Recantation.

(Vgl. ook Robertson, 1989:20).

Uit die voorafgaande behoort dit duidelik te blyk waarom die kind dikwels of nie bereid is om in ' $n$ ope hof oor sy wedervaringe te getuig nie, of sy aanvanklike weergawe aan die polisie in die hof verander. Vervolgens word enkele van bogenoemde kenmerke nader toegelig. Daar moet egter in gedagte gehou word dat die kenmerke met mekaar verband hou en nie altyd waterdig van mekaar geskei kan word nie.

\subsection{Geheimhouding}

Die kind word dikwels in kruisondervraging verwyt omdat hy nie vroeër die molestering bekend gemaak het aan iemand wat hy kan vertrou nie. Hierdie standpunt neem nie in ag dat fisiese geweldstoevoeging of dreigemente daartoe soms as waarborg van stilswye by baie kinders dien nie. Daarbenewens word die kind se swye in baie gevalle gekoop met geskenkies, lekkernye of met die belofte van een of ander persoonlike voordeel vir die kind (byvoorbeeld die versekering van 'n rol in 'n toneelstuk, ensovoorts.) Vir 'n klein kindjie is die "voorreg" om 'n deelgenoot in 'n geheim te wees, hoe nadelig dit ook al vir sy eie fisiese en geestelike welsyn mag wees, voldoende beloning. Daarbenewens vrees die kind dat indien die molestering bekend word, sy naasbestaandes en vriende hom sal verwerp. Gevolglik swyg die kind en die molestering gaan voort.

\section{3 'n Gevoel van hulpeloosheid}

Gedurende die tydperk van aanhoudende molestering ontwikkel die kind 'n gevoel van hulpeloosheid. Hy maak homself wys dat hy vasgevang is in 'n situasie waaruit hy nie kan ontvlug nie. Die meeste kinders word immers opgevoed om nie die optrede van volwassenes onnodig te bevraagteken nie. Dit is dus te begrype dat die kind huiwerig is om gevalle van molestering bekend te maak, veral omdat hy uit die staanspoor aanvaar dat sy weergawe van die gebeure nie geglo sal word nie. Derhalwe verduur 
die kind eerder die molestering.

\subsection{Skuldgevoelens en vrees vir verdere molestering}

Die kind se "deelname" aan die molesteringsproses, hoe onwillig sy aandeel daarin ook al mag wees, bring oorweldigende skuldgevoelens teweeg. Daarby ervaar hy ook aggressie teenoor die molesteerder en vrees hy verdere molestering. Sy emosies ry wipplank tussen die genoemde aggressie en vrees, en sy vrees vir verwerping deur sy naasbestaandes en of vriende. Hierdie gevoelens van die kind neem in intensiteit toe indien die molesteerder een van sy ouers is. Die kind se liefde vir die ouer, sy behoefte aan sekuriteit en sy vrees vir verwerping verhoed hom om die molestering openbaar te maak. Hierbenewens twyfel hy dikwels oor die vermoë van die "onskuldige" ouer om hom teen verwerping en verdere molestering deur die "skuldige" ouer te beskerm.

Indien die kind uiteindelik sover kom om die molestering te rapporteer, gebeur dit dikwels dat hy uit die ouerhuis verwyder word en in 'n plek van veilige bewaring geplaas word. In ander gevalle word die kind egter in die ouerhuis gelaat en die molesteerder in hegtenis geneem en aangehou. Ten einde te verhoed dat die kind wat homself in so 'n situasie bevind onnodige gevoelens van verwerping en skuld ervaar, is dit van kardinale belang dat hy so gou moontlik deskundige leiding ontvang. Ontbreek sodanige hulp, lei dit dikwels daartoe dat die kind homself verantwoordelik hou vir die verbrokkeling van die gesinsverband. In 'n poging om die gesinseenheid te behou, gebeur dit by herhaling dat die kind onder kruisondervraging sy aanvanklike weergawe van die gebeure verander of weier om te getuig. Dit kan uiteraard tot gevolg hê dat die oortreder onskuldig bevind word en die kind teruggeplaas word in 'n sogenaamde liefdevolle huis waar die molestering voortgaan.

\section{Voorgestelde aanpassing van die regsproses}

\subsection{Identifikasie}

Die molesteerder is gewoonlik 'n ouer, stiefouer, familielid of ander persoon wat in 'n vertrouensverhouding met die kind staan, byvoorbeeld 'n musiek- of sangonderwyser (vgl. Robertson, 1989:6-8). Die molesteerder is dus gewoonlik nie vir die kind 'n vreemdeling nie, en is die vraagstuk van identifikasie irrelevant. In die enkele uitsonderingsgevalle waar die kind wel 'n identifikasieparade moet bywoon, word aan 
die hand gedoen dat identifikasie plaasvind terwyl die kind buite sig van die molesteerder is, byvoorbeeld waar die kind agter eenrigtingglas staan. Dit sal die huidige gebruik uitskakel dat die kind die verdagte moet aanraak by identifikasie.

\subsection{Die gebruik van anatomies korrekte poppe en sketse}

Onder simpatieke leiding kan die kind aan die hand hiervan duidelik illustreer wat met hom gebeur het. In gevalle waar die kind egter botweg weier om enigiets te sê, is die geuruik van hierdie hulpmiddels van weinig waarde. Dit is wenslik dat deskundiges soos sielkundiges en of psigiaters die kind se illustrasies aan die hand van poppe en sketse vir die ondersoekbeampte of die hof sal interpreteer.

\subsection{Behoorlike voorbereiding van die kindergetuie deur die staatsaanklaer}

As gevolg van 'n swaar werkslading, het 'n staatsaanklaer in landdroshofverhore dikwels nie tyd om die kind behoorlik voor te berei vir getuienislewering en kruisondervraging nie. Dikwels sien die aanklaer die kind vir die eerste keer wanneer die kind die getuiebank betree. In die hooggeregshof, waar die hofrol gewoonlik lank reeds voor die verhoor vasgestel word, gebruik die staatsadvokaat hierdie geleentheid om, soms herhaaldelik, met die kind te konsulteer. Behoorlike voorbereiding van die kindergetuie is 'n onontbeerlike vereiste in enige saak, nie alleen omdat die kind ingelig kan word oor die prosedure nie, maar ook omdat hy hierdeur meer op sy gemak gestel kan word. Hierdie voorbereiding van die kindergetuie kan egter steeds nie die volgende twee probleme in alle gevalle ondervang nie:

* die vereiste dat hy in die teenwoordigheid van die beskuldigde moet getuig, en

* die vereiste dat hy aan kruisondervraging onderwerp moet word.

\subsection{Regsbystand aan die kindergetuie}

'n Voorstel dat 'n gesinsadvokaat vir die kind aangestel moet word om sy belange in die hof te behartig, is na my mening tereg deur die Regskommissie (1989:32) verwerp. Hierdie funksie behoort deur die aanklaer vervul te word. 'n Aanklaer wat behoorlik toegerus is, sal ook hierdie verpligting na behore kan uitvoer. 


\subsection{Wysiging van die Strafproseswet}

\subsubsection{Die Israeliese stelsel}

Volgens die Israeliese prosedure word 'n kinderondersoekbeampte onmiddellik na rapportering van die molestering belas met die ondersoek van die klagte. Die ondersoekbeampte, wat gewoonlik 'n goed opgeleide persoon is, hanteer uitsluitlik die klagte van die kind, neem sy of haar verklaring af en stel vas of die klagte gegrond is. Die ondersoekbeampte (gewoonlik 'n sielkundige, of maatskaplike werker of proefbeampte) moet ook vasstel of die kind psigies in staat is om getuienis tydens die verhoor te lewer. Sou die ondersoekbeampte bevind dat die hofproses vir die kind te traumaties sal wees, getuig die ondersoekbeampte namens die kind en word die ondersoekbeampte gekruisvra. Hierdie prosedure is egter slegs beperk tot kinders onder die ouderdom van veertien jaar.

Volgens Hammond \& Hammond (1987:6) hou hierdie stelsel die voordeel in dat 'n toename in rapportering van molestering ondervind word, waarskynlik as gevolg van die besondere beskerming wat dit die kind bied. In die lig hiervan word aan die hand gedoen dat daar oorweging geskenk word aan 'n moontlike alternatiewe stelsel vir Suid-Afrika. Ten opsigte van die voorstelle wat in hierdie verband reeds aan die Regskommissie voorgele is, word telkens twee besware geopper, naamlik 'n mannekrag- en finansiële tekort.

\subsubsection{Die stelsel in die Verenigde Koninkryk}

In die Verenigde Koninkryk (Stevenson \& Sood, 1990:18) word ekstensief gebruik gemaak van video-opnames van die kind se getuienis.

Volgens hierdie stelsel getuig die kindergetuie in 'n vertrek aangrensend aan die hofsaal. Die vertrek is toegerus met televisiemonitors wat deur die voorsittende beampte beheer word. Die kindergetuie is op die skerm sigbaar vir sowel die beskuldigde as die hofpersoneel, en vrae kan dus direk aan die kind gestel en (hoorbaar vir die hof) deur hom beantwoord word. 'n Gemeenskaplike faktor van die Israeliese en Verenigde Koninkryk se stelsels is dus dat die kindergetuie nie in die teenwoordigheid van die beskuldigde hoef te getuig nie.

'n Voorstel ten opsigte van die gebruik van 'n video-opname van die kind se verklaring 
in plaas van getuienislewering, is reeds aan die Suid-Afrikaanse Regskommissie $(1989: 25)$ voorgelê. Dit is ongelukkig deur die Kommissie verwerp, na my mening weens ' $n$ foutiewe interpretasie daarvan.

Die voorstellers, Hammond \& Hammond (Regskommissie, 1989:33) formuleer die regverdiging vir hulle voorstel soos volg:

The acceptance of video-recording made under standardised procedures as altematives to the presence of a child witness would go a long way in solving the moral dilemma with us now. (My beklemtoning).

Ten spyte daarvan dat die voorstel duidelik neerkom op 'n alternatief vir persoonlike verskyning van die kindergetuie, interpreteer die Regskommissie dit skynbaar as 'n voorstel wat sou neerkom op selfstawing van getuienis. Selfstawing druis in teen die reëls van die bewysreg wat bepaal dat 'n getuie sy weergawe nie mag bevestig deur middel van getuienis van 'n soortgelyke verklaring wat hy vroeër oor dieselfde insident buite die hof gemaak het nie, en is derhalwe ontoelaatbaar. Die Regskommissie (1989:33) formuleer sy standpunt soos volg:

Die video-opname van so 'n verklaring sal, in die hande van die aanklaer, ontoelaatbaar wees omdat (a) dit blote selfstawing is, (b) as vorige ooreenstemmende verklaring ontoelaatbaar is, en (c) irrelevant is in die lig van die regsvereiste dat die getuie self viva voce in die hof moct getuig.

'n Video-opname van die aanvanklike verklaring van die kind aan die ondersoekbeampte of 'n maatskaplike werkster, kan egter groot voordele vir sowel die kind as die regsproses inhou. Die opname skakel voortdurende herhaling van die gebeure deur die kind uit. Dit verhoed dat sy of haar gevoel van skaamte en skuld geïntensifiseer word (Key, 1988:56).

\subsubsection{Voorgestelde wysigings aan die Strafproseswet}

Ten einde te verhoed dat die kindergetuie aan die dikwels vyandige atmosfeer in die hofsaal blootgestel word, is dit noodsaaklik om die bestaande stelsel aan te pas op ' $n$ wyse wat nie noodwendig ' $n$ finansiële of mannekragprobleem tot gevolg sal hê nie en terselfdertyd die behoefte van die kind in ag sal neem. Na my mening bestaan daar reeds prosedures in die Strafproseswet wat aangepas kan word om hierdie oogmerke te bereik. 


\subsubsection{Prosedure kragtens artikels 77 en 79 van die Strafproseswet}

Ingevolge artikels 77 en 79 van die Strafproseswet word persone wat oënskynlik nie verhoorbaar is nie, of persone wat beweer dat hulle ten tye van die pleging van die misdryf ontoerekeningsvatbaar was, vir' $n$ tydperk van dertig dae na 'n inrigting verwys vir waarneming. Gedurende hierdie tydperk word sielkundige toetse en konsultasies met die pasiënt uitgevoer deur 'n paneel wat kan bestaan uit twee of drie psigiaters. Die paneel bestaan uit drie psigiaters, naamlik 'n hofpsigiater, 'n staatspsigiater en ' $n$ verdedigingspsigiater in gevalle van halssake, of slegs eersgenoemde twee in alle ander gevalle. $\mathrm{Na}$ afloop van die dertig dae doen die paneel verslag aan die hof aangaande hul bevinding. Die verslag kan een van twee vorms aanneem:

* Indien die paneel eenparig is in hul bevinding, word 'n skriftelike verslag tot dien effekte by die hof ingedien.

* Indien die paneel se verslag nie eenparig is nie, of indien wel eenparig maar die staat of verdediging aanvaar nie die verslag nie, word die mondelinge getuienis van die psigiater/s aangebied. Die hof beslis dan die vraag na verhoorbaarheid op grond van hul getuienis.

Uit voorgaande is dit dus duidelik dat die Suid-Afrikaanse regstelsel nie van 'n geestesongestelde persoon verwag om self getuienis af te lê of gekruisvra te word aangaande sy beweerde geestesongesteldheid nie.

\subsubsection{Prosedure kragtens hoofstuk 20 van die Strafproseswet}

'n Verdere prosedure waarvoor hoofstuk 20 van die Strafproseswet voorsiening maak, behels ' $n$ voorlopige ondersoekproses in plaas van 'n formele kriminele verhoor. Hierdie ondersoek vind plaas in 'n hofsaal en alle bewysregtelike en prosesregtelike reëls is steeds van toepassing (byvoorbeeld reëls met betrekking tot getuienislewering asook hoof-, kruis- en herondervraging van getuies). Die verdagte is egter in hierdie proses nie 'n beskuldigde nie en geen aanklag word aan hom gestel waarop hy moet pleit nie. $\mathrm{Na}$ afloop van al die getuienis en op grond daarvan, kan die aanklaer aan die einde van die verhoor 'n formele aanklag aan die verdagte stel waarna hy gevra word om daarop te pleit. 'n Kriminele verhoor volg na afloop van die pleitstadium. Die voordeel van dié prosedure behels dat die getuienis reeds aangehoor is. Die hofnotule kan bloot ingelewer word en die beskuldigde op sy verdediging geplaas word. Die 
moontlikheid van 'n pleit van skuldig (wat impliseer dat getuienislewering deur getuies uitgeskakel word) word hierdeur verhoog.

\subsubsection{Voorgestelde prosedure}

Na my mening kan 'n kombinasie van die bogenoemde prosedures soos volg met vrug toegepas word op alle verhore waarin 'n gemolesteerde kind behoort te getuig.

* Sodra die molestering aangemeld word, is dit noodsaaklik om die kind onmiddellik in 'n "plek van veilige bewaring" op te neem. Op hierdie wyse kan op 'n baie vroeë stadium reeds aan die gemolesteerde kind die nodige kundige ondersteuning gebied word. Die "plek van veilige bewaring" kan byvoorbeeld die kindersaal van 'n hospitaal wees.

* Gedurende die tydperk wat die kind in die hospitaal of inrigting is, word 'n paneel bestaande uit drie sielkundiges of psigiaters aangestel. Die paneel bestaan uit 'n hofpsigiater, 'n staatspsigiater en 'n verdedigingspsigiater. Die paneel stel deurtastende ondersoek in na die beweerde molestering en interpreteer die kind se sketse en demonstrasies ter bepaling van die vraag of die kind wel gemolesteer is en of dit in die psigiese belang van die kind is om aan die hofprosedure blootgestel te word. Aangesien die kind nou ook toeganklik is vir medici, kan vasgestel word of die kind fisiese beserings opgedoen het of nie, en die nodige behandeling kan daarvoor verskaf word. 'n Fisieke ondersoek is van wesenlike belang aangesien dit noodsaaklike stawing kan bied vir 'n bewering van molestering.

* Die tydperk waarbinne bogenoemde ondersoeke en waarneming geskied, behoort nie dertig dae te oorskry nie. Toestemming vir verlenging van die tydperk kan alleen deur die Prokureur-generaal verleen word na 'n gemotiveerde aansoek van die paneel.

- Aan die einde van die periode van dertig dae doen die paneel verslag aan die hof. Dieselfde beginsels, soos hierbo uiteengesit ten opsigte van die paneel se verslag ingevolge artikels 77 en 79 behoort in hierdie geval van toepassing te wees. Die paneel maak ook 'n aanbeveling ten opsigte van die geskiktheid al dan nie van die kind om self te getuig. 
* In plaas daarvan dat die paneel verslag doen tydens 'n kriminele verhoor, behoort die prosedure in hoofstuk 20 van die Strafproseswet, soos hierbo uiteengesit, gevolg te word.

* Gedurende hierdie voorlopige ondersoek bied die staatsaanklaer die getuienis van een van die psigiaters of sielkundiges aan (indien die verslag eenparig is), asook alle ander stawende getuienis (behalwe dié van die gemolesteerde kind).

* Indien die paneel van oordeel is dat geen molestering plaasgevind het nie, volg geen kriminele vervolging nie. Is die teendeel egter waar, dra die staat die bewyslas om 'n prima facie-saak daar te stel. Dit word gedoen by wyse van deskundige getuienis. Indien 'n prima facie-saak bewys is, stel die aanklaer aan die einde van die ondersoek die gepaste aanklag aan die verdagte.

* Die hierbo bespreekte prosedure behoort slegs van toepassing te wees op kindergetuies onder die ouderdom van twaalf jaar in die lig van die onweerlegbare vermoede dat 'n kind onder die ouderdom van twaalf jaar nie tot geslagsgemeenskap kan toestem nie. 'n Diskresie kan egter in wetgewing aan die Prokureurgeneraal verleen word om in ander buitengewone gevalle eweneens van hierdie prosedure gebruik te maak (byvoorbeeld indien die kind ouer as twaalf is en die paneel aanbeveel dat die hofprosedure te traumaties vir die kind sal wees).

\subsubsection{Voordele van die voorgestelde prosedure}

* Die kindergetuie word effektief beskerm teen die hofprosedure wat traumaties kan wees, aangesien die kind nie self getuig nie.

* In die lig van bogenoemde beskerming behoort aanmelding van molestering toe te neem.

* Die beslissing of in twyfelagtige gevalle vervolg behoort te word, word uit die hande van die Prokureur-generaal geneem en aan die hof oorgelaat. Die hof grond sy besluit op getoetste getuienis, 'n voordeel wat in normale omstandighede nie vir die Prokureur-generaal beskikbaar is nie.

* Hierdie prosedure strek ook tot voordeel van die verdagte in dié sin dat 'n besluit om te vervolg eers geneem word nadat sekere getuienis getoets is deur kruisonder- 
Die gemolesteerde kind as getuie

vraging.

* Aangesien hierdie voorstel op bestaande prosedures gebaseer word, het dit geen bykomende finansiële uitgawe of mannekragtekort tot gevolg nie.

\section{Samevattende konklusie}

In die lig van die probleme wat die gemolesteerde kind ten opsigte van die tans geldende prosedure in die strafhowe ondervind, het dit gebiedend noodsaaklik geword om 'n alternatiewe proses te vind. Behalwe getuienislewering by wyse van videoopname, is reeds voorgestel dat die kind in 'n speelkameratmosfeer moet getuig en dat die kruisondervraging van die beskuldigde of regsverteenwoordigers aan die kind vertolk word deur 'n sielkundige of maatskaplike werker. Hierdie voorstelle is ten spyte van hulle meriete, op grond van finansiële oorwegings en 'n mannekragtekort nie geïmplementeer nie. Daar bestaan egter na my mening geen regverdiging vir die behoud van die reël dat die kindergetuie gekruisvra moet word nie, terwyl daar geredelike afstand gedoen word van die reël dat die kindergetuie in die teenwoordigheid van die beskuldigde moet getuig.

Deur 'n blote wysiging van die Strafproseswet, soos hierbo aan die hand gedoen, kan die probleme van die gemolesteerde kind as getuie ondervang word. Die implikasies van die voorgestelde wysiging ten opsigte van finansiële en mannekragoorwegings behoort gering te wees.

Dat onmiddellike verandering noodsaaklik is, blyk duidelik uit die volgende:

There is a feeling of urgency shared by a growing number of people who have observed from first hand the plight of a small, already victimised person trying to remain composed under the full onslaught of the adversarial legal system. Would one subject your child to this in the interest of justice? Many parents will not, preferring to protect their child from court abuse at the expense of bringing to justice a child abuser (Hammond \& Hammond, 1987:5)

\section{BIBLIOGRAFIE}

HAMMOND, J.C. \& HAMMOND, E.J. 1987. Justice and the child witness. SASK:3-20. HIEMSTRA, V.G. 1987. Suid-Afrikaanse strafproses. Durban : Butterworths. KEY, J.J.A. 1988. The child witness: the battle for justice. De Rebus :54-58, Jan. MYERS, J.E.B. 1987. Child witness law and practice. New York: Wiley (Reeks: Trial Practice Library). REGSKOMMISSIE. 1989. Beskerming van kindergetuies. Projek 71, Werkstuk 28:35-33. 
ROBERTSON, G. 1989. Sexual abuse of children in South Africa. Hammanskraal : Unibook Publishers. SCMIDT, C.W.H. 1989. Bewysreg. Durban : Butterworths.

STEVENSON, K. \& SOOD, U. 1990. The celluloid child witness. The Law Society's Gazette, 10:17-18, Jan

\section{WETTE}

Strafproseswet 51 van 1977.

\section{HOFSAKE}

$S$ v Azov $19741 \mathrm{SA} 808(\mathrm{~T})$

$S \vee$ Eyden 19824 SA 141 (T)

$S v$ Gidi and Another 19844 SA 537 (K)

$S v$ Gwebu 19884 SA 155 (W)

$S v$ Motlatla 19751 SA 814 (T)

$S v$ Omar 19822 SA $357(\mathrm{~T})$

$S \vee$ Tyebela 19892 SA $22(\mathrm{~A})$

$S v V$ Ongerapporteer, saaknommer CC $438 / 85$

Woji v Santam Insurance Co Ltd 1981 1 SA 1020 (A) 
